Barbara Zmuda

https://doi.org.10.26881/ae.2018.15.09

Uniwersytet Gdański

barbarabalbinazmuda@gmail.com

\title{
Znaczenie intermedialnych środków wyrazu w grach wideo a recepcja ich treści i formy
}

\begin{abstract}
Wstęp
Gry wideo, podobnie jak dzieła współczesnej kinematografii lub sztuki teatralne, są utworami niezwykle złożonymi. W przeciwieństwie do innych mediów są reprezentowane nie tylko przez oprawę audiowizualną, ale oferują również pewien stopień interaktywności, pozwalając użytkownikowi oddziaływać na utwór. Umożliwia to twórcom gier stosowanie zupełnie nowych, charakterystycznych wyłącznie dla tego medium, środków wyrazu. Warstwa kulturowa gier wideo, a przede wszystkim liczne komunikaty audiowizualne, są bardziej lub mniej świadomie rejestrowane przez graczy, co intensyfikuje ich funkcję kulturotwórczą. Zabiegi te mogą być intencjonalnie wykorzystywane przez twórców do nadania grze cech narzędzia ideologicznego lub edukacyjnego, jednak należy pamiętać, że mechanizmy te zachodzą także bez intencji autora. Kwestia intermedialnych środków wyrazu jest zagadnieniem wielopłaszczyznowym, dlatego w niniejszym artykule zostaną omówione jedynie jego wybrane aspekty.
\end{abstract}

\section{Elementy gier}

Aby w pełni zrozumieć złożoność gier komputerowych, a także by móc rozpatrywać je jako swego rodzaju specyficzne teksty kultury, należy dokonać podziału danej gry jako całości na mniejsze, dające się zdefiniować elementy składowe. Ze względu na nierozerwalny związek tego medium ze skomputeryzowanymi platformami (a więc nie tylko z komputerem, ale też z konsolami lub urządzeniami mobilnymi), Lev Manovich wskazuje dwie warstwy gry komputerowej: 
- cyfrową, związaną (z punktu widzenia twórcy) z rozwiązaniami programowymi, kodem źródłowym i (z punktu widzenia odbiorcy) z kompetencjami technologicznymi użytkownika,

- kulturową, rozpatrywaną jako zespół audiowizualnych bodźców, które tworzą dający się odczytać i jednoznacznie zinterpretować wirtualny świat oraz często także pewną opowieść (Manovich, cyt. za: Gałuszka 2017: 81).

Dodatkowo Damian Gałuszka rozumie grę komputerową jako formę symulowanej, dwu- lub trójwymiarowej przestrzeni rozgrywki, do której da się wirtualnie „wejść" i która staje się przez to obszarem interakcji społecznej (Gałuszka 2017: 81). Przestrzeń ta, jako element gry, jest w pewnym sensie ogniwem spajającym dwie wymienione wcześniej warstwy. Warstwa kulturowa może bowiem być odczytywana wyłącznie za pośrednictwem tej przestrzeni istniejącej dzięki rozwiązaniom technologicznym zawartym w warstwie cyfrowej.

Przedstawiony podział $w$ pewnych przypadkach może zostać uznany za kompletny, jednak pomijany jest w nim kluczowy element decydujący o uznaniu dzieła za grę, mianowicie sama mechanika rozgrywki, będąca esencją fenomenu tego medium. Alternatywny podział gry na czynniki przedstawia między innymi Krzysztof Gonciarz, który wskazuje następujące składowe:

- treść (ang. content) - jest to cała zawartość merytoryczna i audiowizualna dzieła, czyli wszystkie elementy tekstowe, obrazy, nagrania dźwiękowe, trójwymiarowe modele. W przypadku gier komputerowych treścią jest całość oprawy artystycznej, a także fabuła gry (jeśli występuje) i wszystkie związane z nią struktury narracyjne,

- rozgrywka (ang. gameplay) - jest to ogół rozwiązań i elementów, które stanowią o wzajemnym oddziaływaniu gracza i gry. Na rozgrywkę składa się nieskończenie wiele kwestii związanych z połączeniem między graczem i grą, wszelkie przejawy interakcji między nimi, umożliwiane przez zaprogramowaną mechanikę gry,

- technologia - czynnik zapewniający działanie gry jako programu komputerowego. Są to narzędzia, kod źródłowy, silnik graficzny, edytory i efekty, które sprawiają, że odbiorca jest w stanie odczytać dwa pozostałe czynniki jako interfejs i zaprojektowaną przez twórców audiowizualną reprezentację wirtualnego świata (Gonciarz 2011: 12-14).

Każda, nawet możliwie najprostsza gra komputerowa, jest zbudowana z elementów należących do tych trzech składowych. Są one tak elementarne, a jednocześnie tak obszerne, że nie sposób pominąć którąkolwiek. Wszystkie trzy płaszczyzny są nierozerwalnie powiązane ze sobą, a jakość tej więzi decyduje o sukcesie artystycznym i komercyjnym gry. 


\section{Gry jako sztuka}

Przestrzeń wirtualnego świata, istniejąca dzięki rozwiązaniom technologicznym, staje się zatem kanałem transmitującym treść użytkownikowi. Z jednej strony gracz jest przede wszystkim skupiony na rozgrywce i na osiąganiu wyników, a z drugiej biernym odbiorcą licznych intermedialnych komunikatów. Współczesne gry wideo stają się w tym kontekście swego rodzaju dziełami sztuki, prezentowanymi w bogatej, multimedialnej formie. Proces produkcji wysokiej klasy gier wideo wymaga zaangażowania setek artystów, podobnie jak przy wysokobudżetowych produkcjach kinowych. Oprawa graficzna gier jest wykonywana we współpracy z profesjonalnymi malarzami, rzeźbiarzami i fotografami pracującymi w środowisku cyfrowym zgodnie z klasycznymi zasadami panującymi w dziedzinie sztuk plastycznych. Ścieżki dźwiękowe powstają przy udziale światowej klasy kompozytorów, a nad płynną narracją przypominającą kinowe doświadczenia czuwa sztab profesjonalnych filmowców. Jednak sukces artystyczny nie jest zarezerwowany wyłącznie dla wysokobudżetowych produkcji. Przywołać można chociażby stanowisko Małgorzaty Łuszczak, dziekan Wydziału Artystycznego Uniwersytetu Śląskiego, która zauważa w ostatnich latach wzrost znaczenia rynku gier niezależnych (tzw. indie games), tworzonych przez niewielkie, kilkuosobowe zespoły lub nawet przez indywidualnych twórców. Gry indie są wolne od wszelkich ograniczeń narzucanych przez producentów, dlatego charakteryzują się nieszablonowym podejściem do rozgrywki i oprawy audiowizualnej. Mimo niskich nakładów finansowych gry niezależne zyskują w ostatnich latach dużą popularność, jednocześnie często reprezentując równie wysokie standardy artystyczne co droższe produkcje (Łuszczak 2017). O wartości artystycznej dzieła cyfrowego nie decyduje jakość techniczna utworu, a raczej to, czy wywołuje on zamierzone przez projektanta reakcje u odbiorcy. Ujawnia to narracyjny potencjał minimalizmu w kulturze i udowadnia, że gracze nie oczekują jedynie intensywnych doświadczeń zmysłowych i rozrywki, ale też doceniają utwory kładące nacisk na nastrojowość i wywoływanie emocji.

Przykładem gry indie cechującej się wysoką wartością artystyczną jest Limbo. Charakteryzuje się minimalistyczną oprawą dźwiękową i surrealistyczną, czarno-białą, dwuwymiarową grafiką, przywołując atmosferę kina noir i filmów z okresu niemieckiego ekspresjonizmu. Jest to historia chłopca poszukującego swojej zaginionej siostry w nieprzyjaznym świecie symbolizującym „krawędź piekła” lub senny koszmar. Sama rozgrywka, pełna zagadek logicznych i wyzwań zręcznościowych, jest wymagającym i satysfakcjonującym doświadczeniem, a oniryczna atmosfera w połączeniu $\mathrm{z}$ mrocznym tonem opowieści buduje przytłaczający obraz świata, zmuszający do refleksji między innymi nad naturą śmierci. Twórcy przewidzieli możliwość zastąpienia drastycznych scen śmierci efektem ściemniania ekranu, dzięki czemu niewątpliwa wartość artystyczna produkcji może być bezpiecznie prezentowana również młodszym graczom. 
Poza najpopularniejszymi konwencjami, czyli stylistyką fantasy i science fiction, również tematyka gier jest tak różnorodna jak ta podejmowana przez inne dziedziny sztuki, co skutkuje powstawaniem ludycznych odpowiedników różnych gatunków filmowych i literackich. Wśród gier mamy więc do czynienia z komediami, horrorami, thrillerami, erotykami, kryminałami, romansami, dramatami psychologicznymi i wieloma innymi kategoriami. Wymieniona różnorodność dotyczy jedynie tematyki podejmowanej przez grę, a przecież w połączeniu z mnogością możliwych gatunków gier (rozumianych jako rodzaj przyjętej mechaniki rozgrywki, co zostało szerzej opisane w pierwszej części tekstu) spektrum potencjalnych rodzajów gier jest porównywalne ze zróżnicowaniem treści występującym w literaturze i filmie. Dodatkowo wszystkie motywy mogą wzajemnie się przenikać, tworząc niespodziewane kulturowe mieszanki. Tak skrajne motywy jak pornografia, okultyzm i satanizm można znaleźć zarówno w grach o stylistyce przypominającej filmowe horrory (na przykład Amnesia: Mroczny Obłęd lub Agony), jak i w utworach humorystycznych (The Binding of Isaac). Ewolucja gier wideo w połączeniu z ich potencjałem narracyjnym pobudza twórców także do podejmowania coraz bardziej wartościowych i dojrzałych tematów. Przykładem tego są gry przedstawiające problemy związane z dojrzewaniem (Life is Strange) lub opowiadające w symboliczny sposób o relacjach rodzinnych (Papo \& Yo).

Łuszczak twierdzi, że praca nad produkcją gier wideo coraz częściej umożliwia realizację wizji artystycznych. Twórcy gier wyrażają w ten sposób swoje osobiste przeżycia, emocje i marzenia (Łuszczak 2017). Ich dzieła często są wykonane z dbałością o najmniejsze szczegóły, z pełną świadomością znaczenia kolorów, symboli i kompozycji. Gry wideo stanowią też szansę dla artystów na eksplorowanie niedostępnych wcześniej rejonów. Umiejętne operowanie przestrzenią lub światłem, które samo w sobie jest wartościowym środkiem stylistycznym, może wybrzmieć ze zdwojoną siłą dzięki nadaniu mu znaczenia istotnego $\mathrm{z}$ punktu widzenia mechaniki gry. Łuszczak przywołuje przykład manipulowania "niemożliwymi” strukturami przestrzennymi w grze mobilnej Monument Valley nawiązującej stylistycznie do dzieł plastycznych Mauritsa Cornelisa Eschera. Gra świateł zyskuje natomiast nowy wymiar w grze Closure, w której elementy wirtualnego świata tracą swoją materialną formę i przestają zachowywać się zgodnie z rzeczywistymi zasadami fizyki, jeśli nie są w danym momencie w żaden sposób oświetlone.

Artyści, którzy współtworzą świat gier komputerowych, skupiają uwagę odbiorców na wykreowanej przez siebie wizji przez wiele godzin. Zdaniem Małgorzaty Łuszczak jest to często o wiele dłuższy czas obcowania ze sztuką niż podczas wizyty w galerii sztuki lub muzeum (Łuszczak 2017). W tym kontekście naturalną tendencję do pośpiesznego pokonywania kolejnych poziomów gry i bezrefleksyjnego odwiedzania zaprojektowanych przez artystów lokalizacji można porównać do próby jak najszybszego przebiegnięcia przez korytarze galerii obrazów, bez zwracania uwagi na to, co jest faktycznie obiektem ekspozycji. Wiele małych dzieł sztuki umieszczonych $\mathrm{w}$ grach jest $\mathrm{w}$ ten sposób ignorowana nawet przez graczy, trudno się więc dziwić, że artystyczna wartość tego medium jest często bagatelizowana. 


\section{Zależność recepcji utworu od zjawiska immersji}

Pisząc o grach komputerowych, nie sposób uniknąć pojęcia immersji. Najogólniej słowo immersja (z łac. immergo - zanurzać się) oznacza zanurzenie fizycznego obiektu w cieczy. W kontekście mediów jest rozumiana jako głębokie zanurzenie w świat danego medium. Janet Murray definiuje immersję jako „wrażenie otoczenia inną rzeczywistością, wywołane zaangażowaniem zmysłów i uwagi osoby, której dotyczy to zjawisko" (Murray, cyt. za: Gałuszka 2017: 41). Według Piotra Kubińskiego w przypadku gier komputerowych czynniki immersyjne sprawiają, że użytkownik do pewnego stopnia izoluje się od świata rzeczywistego - jego zmysły i uwaga są skupione przede wszystkim na świecie wirtualnym (Kubiński 2016: 51). Bez wątpienia istnieje zależność między siłą czynników immersyjnych a jakością rozgrywki. Trudno mówić o dobrej grze komputerowej, jeśli nie angażuje ona użytkownika, podobnie jak nie ma mowy o dobrych książkach lub filmach, jeśli nie są one w stanie przyciągnąć odbiorcy na długie godziny.

Zgodnie z teorią Alison McMahan kluczowym warunkiem zaistnienia immersji podczas rozgrywki jest spójność elementów gry. Zależność między zawartością i elementami występującymi w wirtualnym świecie przedstawionym w grze a przyjętą przez twórców konwencją i sposobem reprezentacji tych elementów musi być zgodny z oczekiwaniami gracza (McMahan, cyt. za: du Vall, Majorek 2014: 99). W praktyce oznacza to, że przykładowo gra opowiadająca przygnębiającą i dojrzałą opowieść o wojnie powinna być oprawiona muzyką utrzymaną w równie poważnej konwencji, a oprawa graficzna powinna być pozbawiona jaskrawych kolorów, co umożliwia wprowadzenie użytkownika w odpowiedni nastrój.

Istotnym czynnikiem wpływającym na zachodzenie zjawiska immersji narracyjnej jest też jakość oprawy audiowizualnej gry. Realistyczna grafika niewątpliwie pogłębia poczucie obecności w innym świecie, podobnie jak podczas oglądania filmu. Warto pamiętać, że nie jest to warunek konieczny dla zaistnienia immersji (ibidem: 99). Najważniejszym czynnikiem zawsze pozostaje zaangażowanie i wyobraźnia samego gracza. Jak w przypadku odbioru innych mediów narracyjnych, na przykład podczas czytania książki lub oglądania filmu, tak i w trakcie rozgrywki niemożliwe jest natychmiastowe zaprezentowanie odbiorcy wszystkich detali i bodźców występujących w przedstawionym świecie. Umberto Eco zauważa, że czytając pierwsze słowa książki, odbiorca nie zna jeszcze kontekstu, a mimo to rozumie treść czytanych słów, bo dzięki podstawowej wiedzy i własnej wyobraźni jest w stanie samodzielnie uzupełnić brakujące elementy (Eco 1996: 2-6). To samo dzieje się podczas gry. Na pierwsze wrażenie wywierane na użytkowniku ma wpływ synteza wielu intermedialnych elementów - wzajemne zależności między ścieżką dźwiękową, obrazem, tekstem, ikonografią a także interfejsem gry. Wszystko to natychmiastowo buduje nastrój utworu, wywołuje napięcie lub inne reakcje u gracza. Prostota i umowność oprawy audiowizualnej, wbrew pozorom, nie jest przeszkodą w odbiorze tych bodźców, jeżeli są one wewnętrznie spójne i zgodne z oczekiwaniami użytkownika (McMahan, cyt. za: du Vall, Majorek 2014: 99). 
Narracyjna rola czynników emersyjnych

Nie wszystkie aspekty wirtualnej rozgrywki wzmagają odczucie zanurzenia w wirtualnym świecie. Nieuniknione jest występowanie elementów o działaniu przeciwstawnym, które Piotr Kubiński określa jako emersja i czynniki emersyjne (Kubiński 2016: 24). Są to przede wszystkim narzędzia pośredniczące między grą a użytkownikiem, jak interfejs gry. Niektórzy twórcy świadomie ograniczają widoczność tych składowych do absolutnego minimum, jak na przykład w grze The Witness polegającej na eksploracji opuszczonej wyspy i rozwiązywaniu zagadek logicznych, w czym graczowi nie przeszkadzają absolutnie żadne elementy interfejsu. W większości gier wideo interfejs jest jednak niezbędny do sprawnej interakcji między grą a użytkownikiem, czego przykładem mogą być „celowniki” umieszczone w centrum ekranu w większości tzw. strzelanek lub obecne w klasycznych grach wideo ikony serduszek informujące gracza o kondycji postaci. Niektóre elementy interfejsu można zastąpić systemem fabularyzowanych oznak, które Piotr Kubiński nazywa semeionami (ibidem: 208-210). W tym przypadku gracz przyjmuje dodatkowe informacje dotyczące mechaniki gry nie ze standardowego interfejsu, ale odczytuje je na podstawie audiowizualnych struktur narracyjnych. Przykładem może być ocenianie kondycji fizycznej piłkarzy w grze Fifa na podstawie ich zachowania lub szacowanie poziomu zniszczeń kierowanego w grze wyścigowej pojazdu na podstawie wizualnych oznak, takich jak wgniecenia na masce, zarysowania itp. (ibidem: 209-211). To, czy taki diegetyczny komunikat zostanie poprawnie zinterpretowany, zależy od użytkownika.

Innym przykładem czynników, których wartość jest zależna od wiedzy osoby interpretującej, są tzw. aluzyjne parafrazy, czyli umieszczone w grach wideo humorystyczne odniesienia do innych dzieł lub zjawisk, wymagające znajomości dodatkowego kontekstu kulturowego (ibidem: 99). Zabiegi te są szczególnie interesujące, ponieważ ten sam element wirtualnego świata może być przez jedną osobę odebrany w kategoriach humorystycznych, a przez inną całkowicie ignorowany (warunkiem jest jednak spójność takiego komunikatu z konwencją przyjętą w utworze).

\section{Zasoby kulturowe gier wideo}

Wymienione powyżej mechanizmy odnoszą się do recepcji gier wideo przez ich użytkowników. Z jednej strony interpretacja komunikatów jest zależna od znajomości kontekstu kulturowego, a $\mathrm{z}$ drugiej gry wideo jako rozwijające się medium same mają coraz większy wpływ na kreowanie świadomości odbiorców. Michał Sołtysiak jest przekonany, że motywy i tropy kulturowe, które obserwujemy w tekstach kultury, w tym także w grach, są odzwierciedleniem ludzkich przekonań i wiedzy o rzeczywistej historii i społeczeństwie. Wszystkie treści, które, nawet nieświadomie, zapamiętujemy z gier, użytkownicy rozpoznają na długo po 
zakończeniu rozgrywki (Sołtysiak 2017: 220). Nie sposób więc zaprzeczyć, że gry komputerowe stały się dziełami kulturotwórczymi - nie tylko czerpią garściami z nauk i istniejących tekstów kultury, ale też same mają swój udział w kreowaniu kultury masowej, stając się czymś więcej niż tylko ludycznymi, bezrefleksyjnymi utworami (ibidem: 228).

Często inspiracją dla twórców światów wirtualnych jest świat rzeczywisty, dlatego w grach odnajdujemy motywy znane z różnych epok historycznych i kultur przedstawione $\mathrm{w}$ różnych konfiguracjach, wzbogacone o elementy fantastyczne bądź detale pozornie zupełnie niepasujące do przyjętej stylistyki. Wynikiem takiej postmodernistycznej mieszanki mogą być teksty kultury o wysokiej wartości artystycznej. Jednocześnie jednak coraz trudniejszym zadaniem dla użytkownika staje się rozgraniczenie elementów bazujących na rzeczywistości od tych dobranych w sposób przypadkowy, a wręcz anachroniczny (Olejniczak 2015: 120-122; Sołtysiak 2017: 229). Sytuacja jest analogiczna do oglądania filmu inspirowanego prawdziwymi wydarzeniami - nigdy nie wiadomo, czy wyidealizowany główny bohater był w rzeczywistości taką osobą, jak przedstawia to film. W przypadku gier również zaciera się granica między fikcją a faktami, tworząc swego rodzaju kulturową mieszankę, która dla specjalisty w danej dziedzinie będzie wręcz karykaturalnym odwzorowaniem rzeczywistości, ale dla masowego odbiorcy może stanowić główne źródło wiedzy na dany temat. Sołtysiak przestrzega, że taki stan rzeczy prowadzi do powielania stereotypów, uproszczeń, przekłamań, mediewalizmów i neomediewalizmów (Sołtysiak 2017: 228-231). Wizerunki i symbole pojawiające się w grach odzwierciedlają masowe wyobrażenia. Przykładem może być chociażby obraz średniowiecznego rycerza, wyobrażanego i przedstawianego niemal zawsze jako postać w ciężkiej, pełnej zbroi płytowej. Taki wizerunek jest ugruntowany w świadomości masowej z powodu tradycji romantycznej, która stworzyła mit rycerza oparty na legendach arturiańskich. Współcześnie niemal każdy wyobraża sobie rycerza jako postać wyposażoną w ciężką, stalową zbroję, chociaż wiedza akademicka udowadnia, że ten rodzaj pancerza pojawił się dopiero pod koniec średniowiecza (ibidem: 231). Podobnie ma się rzecz ze stylem życia w średniowieczu, a także technikami militarnymi tamtego okresu. O ile taktyka wojenna i stosowane formacje oddziałów, jakie widzimy chociażby w grach z serii Total War, mogą często odzwierciedlać rzeczywiste, historyczne sposoby prowadzenia działań wojennych, to techniki walki bronią białą są nagminnie przedstawiane w sposób przekłamany. Pojedynki w grach mają być przede wszystkim spektakularnym widowiskiem audiowizualną ucztą dla odbiorcy. Materiał opublikowany w 2018 roku w serwisie YouTube na kanale TVGRYpl ${ }^{1}$, opracowany we współpracy z Krakowską Szkołą Fechtunku udowadnia, że walki mieczem lub innym rodzajem broni białej przedstawione $\mathrm{w}$ grach (chociaż warto zwrócić uwagę, że te same problemy dotyczą świata filmu i literatury) dalece odbiegają od rzeczywistej sztuki szermierczej,

${ }^{1}$ Materiał dostępny jest w serwisie Youtube pod adresem: https://youtu.be/pdME9u9yQjI [dostęp: 20.04.2018]. 
w której nie uświadczymy efektownych obrotów, piruetów, przewrotów lub walki dwoma mieczami jednocześnie (jak na przykład w grach Skyrim lub Wiedźmin).

Mimo obecności nieuniknionych uproszczeń i neomediewalizmów gry wideo stają się bardzo ważnym składnikiem budującym stan wiedzy historycznej współczesnego społeczeństwa (Sołtysiak 2017: 231). Sołtysiak uważa, że o ile popularne gry wideo niekoniecznie nadają się do przekazywania wiedzy o datach wydarzeń historycznych, to z pewnością mogą służyć prezentacji podstawowych pojęć historiograficznych i mechanizmów rządzących przemianami historycznymi (ibidem: 229-230). Gry mogą też służyć do transmisji wiedzy $\mathrm{z}$ wielu innych dziedzin. Wcielając się $\mathrm{w}$ role specjalistów i profesjonalistów, gracze zapoznają się $\mathrm{z}$ fundamentalną wiedzą niezbędną do podejmowania działań w danej dziedzinie (Wawrzak-Chodaczek 2012: 239). Już w pierwszej połowie XX wieku Paul Cressey zauważył, że media uczą podstawowych pojęć chociażby z zakresu kryminalistyki (Cressey, cyt. za: Krendl, Warren 2004: 59). Gry wideo przekazują jednak tego typu wiedzę w sposób o wiele bardziej plastyczny, użytkownik bowiem od razu ma szansę wykorzystać ją „w praktyce”, w bezpiecznych warunkach komputerowej symulacji (Peterson et al., cyt. za: Sołtysiak 2017: 230). Zakres zagadnień podejmowanych przez twórców gier jest ograniczony jedynie ich wyobraźnią, czego wynikiem są gry prezentujące nieoczywiste, często poważne i osobiste tematy. Twórcy gier takich jak Cart Life, Fran Bow czy Hellblade: Senua's Sacrifice czerpią garściami z dokonań badaczy działających w obszarach antropologii, socjologii i psychologii. Jak relacjonuje Michael Briers, projektanci Hellblade na każdym etapie produkcji konsultowali się ze światowej klasy psychologami i neurologami, aby jak najwierniej odwzorować odczucia towarzyszące osobom zmagającym się z psychozą (Briers 2017: 1). Celem było zwiększenie świadomości użytkowników o występowaniu i skutkach takich dolegliwości. W wywiadzie przeprowadzonym przez Jamesa Lloyda twórcy twierdzą, że efekty towarzyszące rozgrywce zostały zaprojektowane zgodnie z opisami dostarczonymi przez osoby cierpiące na te same przypadłości co główna bohaterka opowieści, czego skutkiem jest intencjonalne wprowadzenie do gry niepokojących, a czasem wręcz przerażających anomalii wizualnych i dźwiękowych (Lloyd 2018). Dzięki tym zabiegom gra w niezwykle plastyczny sposób pozwala graczowi wczuć się w rolę osoby słyszącej głosy w swojej głowie, niepotrafiącej odnaleźć swojego miejsca w świecie. Chociaż produkcja jest pełna elementów fantastycznych, takich jak demony, magia i wymyślny system walki, zawiera ona też liczne odniesienia do historycznych grup etnicznych (bohaterka prezentowanej opowieści należy do plemienia Piktów) i mitologii celtyckiej oraz nordyckiej. Niezaprzeczalnie powstawanie gier podejmujących tak trudne tematy jest oznaką stopniowego dojrzewania tego medium. Hellblade może być istotnym głosem w dyskusji o społecznej świadomości objawów i skutków chorób psychicznych.

Innym istotnym przykładem wpływu gier na świadomość odbiorców są umieszczone w nich nacechowane ideologicznie komunikaty. Nieraz deweloperzy stosują środki wyrazu wpływające na opinię odbiorcy. Marzena Falkowska twierdzi, że gry stają się wtedy swego rodzaju narzędziem ideologicznym, mającym na celu 
uświadomienie gracza o istotnych problemach społecznych i politycznych (Falkowska, cyt. za: Gałuszka 2017: 84), jednak te same mechanizmy działają podczas niemal każdej rozgrywki bez względu na intencje twórców. Tomasz Majkowski zauważa, że istnieje ważna relacja między „kompasem moralnym” gracza a wszystkimi użytkowanymi przez niego tekstami kultury, bez względu na to, czy treść tych tekstów może zostać subiektywnie określona jako sztuka, reprezentuje wartościowe wzorce i przekazuje wiedzę, czy też wręcz przeciwnie (Majkowski 2011: 96). Związek ten jest podobny do wspomnianej wcześniej relacji między treściami pseudohistorycznymi a oczekiwaniami gracza. Z jednej strony odbiorca odczytuje, ocenia i bardziej lub mniej świadomie przejmuje prezentowane ideologie umieszczone w grach przez deweloperów, a z drugiej treści te odzwierciedlają obecny w zbiorowej świadomości, zgodny z oczekiwaniami odbiorców, obraz świata i kultury.

\section{Badania własne - recepcja treści i formy gier wideo}

Celem prezentowanego badania było zebranie możliwie szerokiego zakresu danych dotyczących recepcji zasobów kulturowych, warstwy wizualnej i stereotypów podczas rozgrywki, a także analiza tych danych w kontekście funkcji kulturotwórczej, z wyszczególnieniem różnic wynikających $\mathrm{z}$ wieku badanych. Badanie przeprowadzono metodą netnograficzną, czyli za pomocą szczególnej formy etnografii przystosowanej do analizowania zjawisk występujących w cyfrowej społeczności, odbywającej się w środowisku internetowym (Kozinets 2012: 93). Przeprowadzono trzydzieści wywiadów pogłębionych z dziećmi, młodzieżą i osobami dorosłymi, których wspólną cechą jest zamiłowanie do gier wideo. W przypadku najmłodszych respondentów miejscem badania była Szkoła Podstawowa nr 13 w Gdyni. Za kanał komunikacyjny pośredniczący w rozmowach ze starszymi badanymi posłużył czat na portalu społecznościowym Facebook. W rezultacie przeprowadzono trzydzieści wywiadów pogłębionych: $10 \mathrm{z}$ dziećmi w wieku wczesnoszkolnym (6-10 lat), 10 z młodzieżą w 13-14 lat (uczniowie siódmej klasy szkoły podstawowej oraz drugiej klasy szkoły gimnazjalnej) oraz $10 \mathrm{z}$ osobami pełnoletnimi w wieku 18-21 lat (uczniowie ostatnich klas liceum i studenci). W badanej grupie dominuje płeć męska: wśród dorosłych znalazła się tylko jedna kobieta, a w grupie młodzieży gimnazjalnej - cztery dziewczęta.

Porównując wypowiedzi rozmówców należących do różnych grup wiekowych, można dojść do wniosku, że niezależnie od dziedziny będącej przedmiotem ich zainteresowania, występują podobne zależności i mechanizmy związane z przyswajaniem zasobów kulturowych przez graczy. $Z$ badania wynika, że dzieci w wieku 6-10 lat są często w pełni świadome fikcyjności światów wirtualnych, ale jednocześnie przyjmują wszelkie zawarte w nich zasoby kulturowe w sposób bezkrytyczny nie zdają sobie sprawy $\mathrm{z}$ potrzeby weryfikowania poznanych $\mathrm{w}$ ten sposób treści. Większość badanych dzieci uważa, że wszystko, czego nauczą się z gry, ma swoje zastosowanie w realnym świecie, czego przykładami są następujące wypowiedzi: 
W Race the Sun uczę się, jak pilotować samolot (Paweł, 7 lat).

Z Contry uczę się, jak się strzela (Paweł, 7 lat).

W Minecrafcie można nauczyć się, jak się ścina drzewa, jak szybko rosną rzeczy, jak zbudować dom (Mateusz, 9 lat).

W Lego Friends uczę się jeździć autem (Dominik, 6 lat).

Najczęściej omawianymi podczas wywiadów motywami kulturowymi był wizerunek historycznych, archetypowych postaci: średniowiecznego rycerza oraz wikinga, a także rola kobiety $\mathrm{w}$ średniowiecznym społeczeństwie. Zgodnie z oczekiwaniami z wypowiedzi dzieci wyłania się spójny, wyidealizowany obraz średniowiecznego rycerza, charakteryzowanego przede wszystkim przez jego wygląd zewnętrzny:

Rycerz ma zbroję i miecz [...] wiking ma taki hełm z rogami i długą brodę (Alex, 8 lat).

Ma hełm żelazny, ma miecz, zbroję, ma swojego konia i jeszcze ma tarczę (Mateusz, 9 lat).

Dzieci, które nie miały jeszcze styczności z lekcjami historii, a często nawet nie rozumieją jeszcze pojęcia epoki średniowiecza, rozpoznają i opisują postacie średniowiecznych rycerzy i wikingów zgodnie z przyjętym w kulturze, stereotypowym schematem, będącym jedynie zniekształconą reinterpretacją rzeczywistej wiedzy historycznej. Tylko jedna osoba $z$ tej grupy odróżniła realną postać rycerza od postaci reprezentowanej w grze Minecraft, która może posiadać nierealne, zaczarowane wyposażenie:

Ma zbroję [...]. Opiszę dwóch rycerzy, pierwszy to taki z normalną zbroją, normalną bronią, taki prawdziwy, a drugi to minecraftowy rycerz w diamentowej zbroi enchantowanej na wszystkie enchanty, luk enchantowany na wszystkie enchanty, miecz też, nieskończoność strzał (Maks, 10 lat).

Młodzież będąca we wczesnym okresie adolescencji przedstawia jeszcze wyraźniejszy obraz wyidealizowanego rycerza i innych motywów pseudohistorycznych, co potwierdza zakorzenienie w świadomości masowej wypaczonego obrazu średniowiecza i licznych neomediewalizmów. Wynika to prawdopodobnie z faktu, że osoby w tym wieku miały styczność $\mathrm{z}$ większą ilością różnorodnych tekstów kultury niż młodsza grupa, a jednocześnie nie posiadają jeszcze wiedzy niezbędnej do sprawdzenia prawdziwości tych motywów. Co więcej, same przyznają, że obraz ten wynika w dużej mierze z prezentacji rycerza w grach, co potwierdza rozpoznawanie i zapamiętywanie tropów kulturowych w wyniku użytkowania tego medium. Dorośli respondenci twierdzili, że są świadomi istnienia stereotypowego wizerunku rycerza w kulturze i że potrafią go rozróżnić od realistycznych postaci 
historycznych. Ich zdaniem wiele gier przedstawia rycerzy w jeszcze bardziej przekoloryzowany i wyidealizowany sposób niż film czy książki, jednak nie stanowi to problemu, pod warunkiem, że wizerunek ten jest umieszczony w grach o nierealistycznej konwencji świata. Jeden z badanych oświadczył, że najbardziej wartościowy model opowieści ukazuje rycerza jako tchórza, który mimo słabości podejmuje działanie, jednak mimo to nie staje się chodzącym ideałem z dnia na dzień:

Taka idealna rycerskość jest podawana nam w różnych historiach. Mocno tego nie lubię, bo w to po prostu nie wierzę. Nie lubię pseudoodważnych bohaterów. Wolę tchórzy, którzy mimo wszystko coś w końcu robią. Sam, grając w niektóre gry, specjalnie zresztą wybierałem niemoralne wybory, tylko dlatego, że wierzyłem, że postać by to zrobiła (Jakub, 21 lat).

Inny z rozmówców zwrócił uwagę na pomijanie w grach problemów związanych z życiem w średniowieczu, na przykład chorób czy braku higieny:

W filmach czy książkach są poruszane takie rzeczy jak choroby czy to, że w wojsku się maszerowało miesiąc $\mathrm{z}$ odciskami na nogach. W grach tego nie ma (Łukasz, 21 lat).

Oprawa wizualna gier wideo była bardzo odmiennie oceniana przez graczy, zależnie od wieku. Większość dorosłych rozmówców wyraziła zachwyt nad jakością grafiki współczesnych produkcji. Dla porównania młodzież często krytykuje grafikę jako nierealistyczną lub wręcz przeszkadzającą $\mathrm{w}$ rozgrywce, a dzieci w ogóle nie zwracają uwagi na kwestie techniczne.

Czasem mnie wkurza grafika, jak jest słaba albo zacina (Fabian, 13 lat).

Mój boże, jaka grafika! Zapiera dech w piersi, jaki realizm udało im się osiągnąć (Michał, 21 lat).

W czasie wywiadów poruszono także temat komunikatów wizualnych celowo umieszczanych $\mathrm{w}$ grach przez twórców w celach marketingowych. $\mathrm{Z}$ wywiadów wynika, że najmłodsi gracze nie są świadomi występowania reklam i lokowania produktów w grach. Wyjątkami było dwóch chłopców:

Reklamy są w grach na telefon, ale ja gram w takie bez reklam (Tomek, 9 lat).

W Five Night's at Freddie's są reklamy, ale takie oszukane (Maks, 10 lat).

Odpowiedzi reprezentantów obu starszych grup wskazywały na wysoką świadomość obecności takich przekazów. Kilku trzynasto- i czternastolatków wspomniało o obecności billboardów w świecie gry Grand Theft Auto 5, przedstawiających reklamy rzeczywistych firm i produktów, na przykład KFC, McDonald's czy Coca-Cola. Billboardy pojawiają się także między innymi w Star Stable - zachęcają 
do korzystania z mikrotransakcji i pobierania dodatkowej, płatnej zawartości gry. Młodzież twierdzi, że nauczyła się nie zwracać uwagi na reklamy i lokowanie produktu podczas rozgrywki:

Reklamy raczej olewam (Fabian, 13 lat).

Nawet jak są, to się na nich nie skupiam, staram się ich nie zauważać (Mateusz, 13 lat).

Zachodzi więc tu interesujący mechanizm filtrowania treści. Respondenci z najstarszej grupy uznają obecność reklam lub innych opiniotwórczych przekazów w grze za wadę, chyba że stanowią one spójny i uzasadniony element przedstawionego świata:

Przyznasz, że dziwnie by było, gdybyś kierując wiedźminem, podeszła do zabitej właśnie wiwerny i znalazła przy niej puszkę Sprite albo paczkę Laysów. Za to w takim GTA by mnie to nie zdziwiło (Michał, 19 lat).

Istotna jest też „subtelność” przekazu - powtarzające się nieustannie billboardy z reklamą Mountain Dew w grze The Hulk są, jak twierdzi jeden z rozmówców, "trochę zbyt oczywiste i trochę rażą" (Michał, 21 lat). Niemniej jednak najwyraźniej spełniają swoją funkcję, skoro zostały $\mathrm{w}$ pamięci na wiele lat. Rozmówcy wypowiadają się na temat komunikatów marketingowych bardzo negatywnie, nazywając takie zabiegi wymuszonymi i „niegodnymi zagrywkami” (Jakub, 21 lat) ze strony twórców.

Kolejnym poruszanym tematem były kontrowersyjne treści, obrazy i symbole obserwowane $\mathrm{w}$ grach. $\mathrm{Z}$ wypowiedzi młodzieży wynika jednoznacznie, że w grach często występują symbole okultystyczne. Są to jednak albo subtelne i humorystyczne wzmianki, które nie pozostawiają wątpliwości co do ich niepoważnego charakteru, albo istotne elementy fabularne, utożsamiane na przykład ze złowrogimi organizacjami. Młodzież najczęściej nie uważa obecności takich treści za pozytywną cechę gier, ale też ich nie potępia - ich zdaniem są one prezentowane w całkowicie niegroźny sposób i gracz może je z łatwością ignorować. Tylko jeden z rozmówców stwierdził, że niewątpliwie budują one odpowiednią atmosferę świata gry (Artur, 14 lat). Młodzi gracze pozytywnie odbierają też ukazywanie w grach religii - jest to istotny składnik budujący realizm, sprawia, że postacie $\mathrm{w}$ grach są bardziej ludzkie i „też potrzebują wiary” (Mateusz, 13 lat).

Dorośli rozmówcy reprezentują podobne podejście do kwestii symboli religijnych i okultystycznych co młodsi gracze, jednak częściej zwracają uwagę na pojawiające się wokół tego kontrowersje. Niektórzy z nich uważają, że twórcy gier coraz częściej przekraczają granice dobrego smaku:

Jest taka gra na temat egzorcyzmów i tam bawią się tą tematyką na wszelki możliwy sposób. [...] rozwój postaci: ministrantowi mogą urosnąć skrzydła i tym podobne... i tu jak dla mnie już się robi przesada (Wojtek, 18 lat). 
Są gry, które są tworzone przez ugrupowania chrześcijańskie, i jak dla mnie nie różnią niczym od Dooma itp., z tym że tutaj wszystko, co robisz, robisz dla Boga (Jakub, 21 lat).

Stereotypy zawsze są w modzie, np. księża pedofile (Sylwia, 19 lat).

Większość respondentów jest jednak obojętna na obecność treści krytykujących religię, pod warunkiem, że mają one naturę satyryczną. Są wtedy traktowane tak samo jak satyra filmowa lub literacka. To samo tyczy się innych treści, które mogą być uznawane za szkodliwe. Zdaniem jednego z rozmówców:

wszystko mocno zależy od intencji twórcy i intencji gracza. Jak się zrobi coś mocno kontrowersyjnego, to trzeba się liczyć z konsekwencjami (Jakub, 21 lat).

Obecność symboli i motywów religijnych jest uznawana przez starszych rozmówców, tak samo jak przez młodszych odbiorców, za bardzo pozytywny i realistyczny element gry. Rozmówcy podkreślają, że niektóre gry wręcz opierają się na religii, która stanowi motyw napędzający akcję lub wiążący różne wątki fabularne w całość, poza tym pojmują ją jako jeden z najważniejszych czynników kulturotwórczych, którego nie da się pominąć w utworze należącym do żadnego medium. Niektóre komunikaty wizualne, niezwiązane bezpośrednio z rozgrywką, są więc świadomie odbierane jako istotny element oprawy graficznej - jako tło budujące nastrój utworu.

\section{Podsumowanie}

Gry wideo są złożonymi tekstami kultury, na których recepcję składają się odmienne, wzajemnie uzupełniające się elementy. Nadrzędną częścią składową każdej gry wideo pozostaje mechanika rozgrywki, ale transmisja właściwej treści gry (a w tym zasobów kulturowych) odbywa się za pośrednictwem licznych struktur narracyjnych i form wizualnych. To właśnie warstwa wizualna pełni zasadniczą funkcję w odbiorze gry jako utworu. Oprawa graficzna dostarcza użytkownikowi licznych bodźców, informuje o postępach w rozgrywce, buduje nastrój utworu, wzmaga immersję narracyjną, a dla niektórych graczy może także stanowić walor artystyczny. Twórcy gier wideo świadomie stosują liczne, coraz bardziej złożone i nieoczywiste zabiegi mające na celu doskonalenie tych procesów, rozszerzając repertuar środków wyrazu charakterystycznych dla gier, co według Piotra Kubińskiego jest podstawą do kształtowania się tradycji tego medium (Kubiński 2016: 310). Jednocześnie coraz częściej w grach można dostrzec komunikaty wizualne nawiązujące do popkultury, historii i nauk pozahistorycznych, co intensyfikuje ich kulturotwórczą funkcję. 


\section{Literatura}

Briers M., 2017, Hellblade and Why Mental Illness Needs the Mainstream Spotlight, PlayStationLifeStyle.net, http://www.playstationlifestyle.net/2017/08/09/hellblade-mental-illness-ninja-theory/\#/slide/1 [dostęp: 13.01.2018].

Eco U., 1996, Sześć przechadzek po lesie fikcji, tłum. J. Jarniewicz, Kraków: Wydawnictwo Znak.

Gałuszka D., 2017, Gry wideo w środowisku rodzinnym: diagnoza i rekomendacje, Kraków: Wydawnictwo Libron.

Gonciarz K., 2011, Wybuchające Beczki - zrozumieć gry wideo, Kraków: KG Tofu Media.

Kłoskowicz M., 2017, Czy gry komputerowe moga być dziełem sztuki?, https://www.us.edu. pl/czy-gry-komputerowe-moga-byc-dzielem-sztuki [dostęp: 9.01.2018].

Kozinets R.V., 2012, Netnografia. Badania etnograficzne online, tłum. M. Brzozowska-Brywczyńska, Warszawa: Wydawnictwo Naukowe PWN.

Krendl K.A., Warren R., 2004, Communication effects of noninteractive media: learning in out-of-school contexts [w:] Handbook of research on educational communications and technology, ed. D.H. Jonassen, Mahwah: Lawrence Erlbaum Associates.

Kubiński P., 2016, Gry wideo. Zarys poetyki, Kraków: Wydawnictwo Universitas.

Lloyd J., 2018, How Hellblade: Senua's Sacrifice deals with psychosis, BBC Science Focus Magazine, https://www.sciencefocus.com/the-human-body/how-hellblade-senuas-sacrifice-deals-with-psychosis/ [dostęp: 13.01.2018].

Majkowski T.Z., 2011, Gry wideo i kultura autentyczności, „Homo Ludens”, nr 1.

Olejniczak P., 2015, Cyfrowa piaskownica. Wzajemne przenikanie się świata gier komputerowych i świata rzeczywistego [w:] Socjologia światów wyobrażonych: fantastyka, gra, rekonstrukcja jako obszar transgresji, red. Z. Lambard, Pszczółki: Wydawnictwo Orbis Exterior.

Sołtysiak M., 2017, Mediewalizmy, neomediewalizm i rola archeologii $w$ badaniu gier, „Homo Ludens”, nr 1.

Vall M. du, Majorek M., 2014, W strone nowej kultury gier komputerowych - od komputeryzacji do smartfonizacji, http://cejsh.icm.edu.pl/cejsh/element/bwmeta1.element. hdl_11089_8882/c/10_du_Vall_Majorek.pdf [dostęp: 23.02.2018].

Wawrzak-Chodaczek M., 2012, Rola gier komputerowych $w$ czasie wolnym młodzieży $w$ wieku adolescencji, „Chowanna”, nr 2, http://bazhum.muzhp.pl/media//files/Chowanna/Chowanna-r2012-t2/Chowanna-r2012-t2-s237-252/Chowanna-r2012-t2-s237-252.pdf [dostęp: 20.02.2018].

\section{Ludografia}

Bethesda Game Studios, 2011, The Elder Scrolls V: Skyrim, Bethesda Game Studios.

Blow Jonathan, 2016, The Witness, Thekla, Inc.

CD Projekt RED, 2015, Wiedźmin 3: Dziki Gon, CD Projekt.

DONTNOD Entertainment, 2015, Life is Strange, Square Enix.

EA Sports, 1994, Fifa, Electronic Arts.

Eyebrow Interactive, 2012, Closure, Eyebrow Interactive.

Grip Thomas, 2010, Amnesia. Mroczny Obłęd, Frictional Games.

Hofmeier Richard, 2010, Cart Life, Hofmeier Richard. 
Killmonday Games, 2015, Fran Bow, Killmonday Games.

Madmind Studio, 2018, Agony, Madmind Studio.

McMillen Edmund, 2011, The Binding of Isaac, Team Meat.

Minority Media Inc, 2012, Papo \& Yo, Minority Media Inc.

Ninja Theory, 2017, Hellblade: Senua's Sacrifice, Ninja Theory.

Playdead, 2010, Limbo, Playdead.

Rockstar Games, 2015, Grand Theft Auto V, Rockstar Games.

The Creative Assembly, 2000, Total War, Sega.

Universal Int. Studios, 2003, The Hulk, Activision Blizzard.

Ustwo games limited, 2014, Monument Valley, Ustwo games.

\section{Streszczenie}

Niniejszy artykuł ma na celu wskazanie intermedialnego charakteru gier wideo, prezentację zjawiska immersji oraz emersyjnych środków wyrazu stosowanych przez twórców gier, a także wpływu tych mechanizmów na kulturotwórczą funkcję tego medium. Przedstawiona została również synteza wypowiedzi graczy na temat zasobów kulturowych przyjmowanych z gier wideo, sporządzona na podstawie trzydziestu wywiadów pogłębionych przeprowadzonych z graczami w różnym wieku. Szczególne znaczenie dla prezentowanego zagadnienia ma wzajemna relacja poszczególnych elementów składowych gier wideo, przede wszystkim warstwy kulturowej i różnorodnych komunikatów wizualnych.

\section{Słowa kluczowe}

gry wideo, gry komputerowe, zasoby kulturowe, immersja, komunikat wizualny

\section{Summary}

Reception of video games content - importance of intermedial means of expression

This article indicates the intermedial character of video games, briefy presents immersive and emmersive means of expression used by game developers and demonstrates impact of these mechanisms on the culture-forming function of this medium. Article also presents a synthesis of players' statements on cultural resources adopted from video games, based on thirty in-depth interviews conducted with players from different age groups. Particularly important part of presented issue is the relationship between various components of video games, especially the cultural layer and visual messages.

Keywords

video games, computer games, cultural resources, immersion, visual message 
